Article

\title{
Serum Malondialdehyde is Associated with Non-Alcoholic Fatty Liver and Related Liver Damage Differentially in Men and Women
}

\author{
Shira Zelber-Sagi ${ }^{1,2, *}$, Dana Ivancovsky-Wajcman ${ }^{1}$, Naomi Fliss-Isakov ${ }^{2,3}$, Michal Hahn ${ }^{4}$, \\ Muriel Webb ${ }^{2,3}$, Oren Shibolet ${ }^{2,3}$, Revital Kariv ${ }^{2,3,+}$ and Oren Tirosh ${ }^{4,+}$ \\ 1 School of Public Health, University of Haifa, Haifa 3498838, Israel; divancov@campus.haifa.ac.il \\ 2 Department of Gastroenterology, Tel Aviv Medical Center, Tel Aviv 6423914, Israel; \\ naomifl@tlvmc.gov.il (N.F.-I.); murielw@tlvmc.gov.il (M.W.); orensh@tlvmc.gov.il (O.S.); \\ revitalk@tlvmc.gov.il (R.K.) \\ 3 Sackler Faculty of Medicine, Tel Aviv University, Tel Aviv 6997801, Israel \\ 4 Institute of Biochemistry, Food Science and Nutrition, The RH Smit Faculty of Agriculture, \\ Food and Environment, The Hebrew University of Jerusalem, Rechovot 76100001, Israel; \\ Michalhahn@pac.ac.il (M.H.); oren.tirosh@mail.huji.ac.il (O.T.) \\ * Correspondence: szelber-s@univ.haifa.ac.il; Tel.: +972-3-6973984 \\ + The last two authors equally contributed to the paper.
}

Received: 25 May 2020; Accepted: 25 June 2020; Published: 2 July 2020 updates

\begin{abstract}
Background: Non-alcoholic fatty liver disease (NAFLD) and steatohepatitis (NASH) are associated with increased oxidative stress and lipid peroxidation, but large studies are lacking. The aim was to test the association of malondialdehyde (MDA), as a marker of oxidative damage of lipids, with NAFLD and liver damage markers, and to test the association between dietary vitamins $\mathrm{E}$ and $\mathrm{C}$ intake and MDA levels. Methods: A cross-sectional study was carried out among subjects who underwent blood tests including FibroMax for non-invasive assessment of NASH and fibrosis. MDA was evaluated by reaction with Thiobarbituric acid and HPLC-fluorescence detection method. NAFLD was diagnosed by abdominal ultrasound. Findings: MDA measurements were available for 394 subjects. In multivariate analysis, the odds for NAFLD were higher with the rise of MDA levels in a dose-response manner, adjusting for age, gender, BMI, and lifestyle factors. Only among men, higher serum MDA was associated of higher odds for NAFLD and NASH and/or fibrosis (OR = 2.59, 95\% CI 1.33-5.07, $P=0.005 ; \mathrm{OR}=2.04,1.02-4.06, P=0.043$, respectively). Higher vitamin E intake was associated with lower odds of high serum MDA level ( $\mathrm{OR}=0.2895 \%$ CI $0.13-0.62, P=0.002)$. In conclusion, serum MDA is associated with NAFLD and markers of NASH or fibrosis among men. Dietary vitamin E may be protective among women.
\end{abstract}

Keywords: fatty liver; lipid peroxidation; antioxidants; oxidative stress

\section{Introduction}

Nonalcoholic fatty liver disease (NAFLD) is emerging as the most common chronic liver condition worldwide, with global prevalence in the general population estimated to be $25 \%$ [1]. NAFLD includes two pathologically distinct conditions: Non-alcoholic fatty liver which is simple steatosis, and non-alcoholic steatohepatitis (NASH) which can progress to liver fibrosis, cirrhosis, and hepatocellular carcinoma (HCC); both conditions are associated with extrahepatic manifestations such as cardiovascular disease [1-3]. Oxidative stress is involved in NAFLD pathogenesis and especially in the onset and progression NASH [4]. Patients with NASH have increased oxidative stress, lipid peroxidation, and inflammation, paralleled with reduced antioxidant defense capacities $[5,6]$. 
Extensive research has identified oxidative stress-induced inflammation with lipid peroxidation, cytokine activation, as well as excess production of reactive oxygen and nitrogen species (ROS/RNS) as possible mechanisms in NASH pathogenesis [7]. During the process of lipid peroxidation, a wide range of pre-inflammatory products are produced which result in progression of the disease. One of these by-products is malondialdehyde (MDA), which is a common marker for oxidative stress. Furthermore, MDA can stimulate hepatic stellate cells to produce collagen which results in fibrosis [8]. An increase in serum oxidative markers (e.g., MDA) paralleled by a decrease in the activity of antioxidants has been observed in patients with NAFLD [9]. Plasma MDA levels were demonstrated to be significantly increased in diabetic or obese NAFLD patients as compared with healthy controls [10]. Moreover, anti-MDA antibodies in 167 biopsy proven NAFLD patients were demonstrated to be associated with higher risk of having advanced fibrosis, but not with necroinflammation [11]. Interestingly, patients with NAFLD were demonstrated to have significantly higher levels of MDA and other oxidative markers in comparison to chronic viral hepatitis patients [12].

Dietary antioxidants could be an effective strategy to prevent NASH. Vitamin E and vitamin C are two major antioxidants, which are fat-soluble and water-soluble, respectively. Vitamin E plays a role in anti-inflammatory activities, gene expression, cellular signaling, and cell proliferation [13]. Vitamin E encompasses a group of 8 plant based molecules; the most abundant form is $\alpha$-tocopherol [14]. Due to its ability to inhibit ROS production during the development of steatohepatitis, vitamin E has been investigated as a therapeutic agent in NAFLD and especially NASH [15]. In experimental studies, vitamin E supplement reduced oxidative stress [16], serum transaminase levels and hepatic steatosis in mouse NASH model [17]. The association between vitamin C dietary intake and NAFLD has been studied, but not extensively, and with conflicting results [18-21].

To our best knowledge, there are no large studies that tested the association of oxidative damage of lipids with human NAFLD and NASH, thoroughly adjusting for metabolic and lifestyle risk factors and evaluating the potential protective role of dietary vitamin $\mathrm{E}$ and $\mathrm{C}$. Therefore, the aim of the current study was first, to test the association of MDA, as a marker of oxidative damage of lipids, with NAFLD and liver damage markers of NASH and fibrosis, and second, to test the association between dietary vitamins $\mathrm{E}$ and $\mathrm{C}$ intake and MDA levels, in a cohort of subjects from general population. We hypothesized that MDA will be related with increased hepatic damage and that dietary intake of these antioxidants will be protective from oxidative damage of lipids.

\section{Materials and Methods}

\subsection{Study Design and Population}

A cross sectional study among 40-70-year-old subjects who underwent screening colonoscopy at the Department of Gastroenterology and Hepatology in the Tel-Aviv Medical Center, and agreed to participate in a metabolic and hepatic screening study between the years 2010 and 2015. Exclusion criteria included: Presence of HBsAg or anti-HCV antibodies, fatty liver suspected to be secondary to hepatotoxic drugs, and excessive alcohol consumption ( $\geq 30 \mathrm{~g} /$ day in men or $\geq 20 \mathrm{~g} /$ day in women). In addition, subjects who reported an unreasonable caloric intake were excluded; below or above the acceptable range for men 800-4000 Kcal/day and for women 500-3500 Kcal/day [22].

The study was approved by the Tel-Aviv medical center IRB committee and all participants signed an informed consent.

\subsection{Data Collection and Definition of Hepatic and Metabolic Variables}

Study participants were invited for a single day visit, in which they underwent fasting blood tests, liver ultrasound, a face-to-face interview using a structured questionnaire, assembled by the Israeli Ministry of Health and used in national surveys [23], including demographic details, health status, alcohol consumption, smoking and exercise habits. In addition, they completed food frequency questionnaire (FFQ). To avoid report bias, the participants were informed of their abdominal 
ultrasonography (AUS) and blood tests results only after completing the questionnaires. Fatty liver was diagnosed by AUS using standardized criteria [24] as previously described [25], performed in all subjects with the same equipment (EUB-8500 scanner Hitachi Medical Corporation, Tokyo, Japan) and by the same experienced radiologist (Webb M).

Presumed NASH and fibrosis were evaluated non-invasively by FibroMax which includes FibroTest, new quantitative NashTest, and SteatoTest, (BioPredictive, Paris, France), and has been validated extensively $[26,27]$. The FibroTest includes serum $\alpha 2$-macroglobulin, apolipoprotein-A1, haptoglobin, total bilirubin, and $\gamma$-glutamyl transpeptidase adjusted for age and gender. The NashTest 2 includes all above and alanine aminotransferase, serum cholesterol, and triglycerides [27]. The presence of fibrosis was defined as $\geq F 2$, corresponding to a value $\geq 0.48$, indicating significant fibrosis [26]. The presence of presumed NASH was defined as $\geq \mathrm{N} 2$, corresponding to a value $\geq 0.50$ [26]. The procedures were those recommended by BioPredictive, including exclusion of non-reliable results [28].

Type- 2 diabetes or pre-diabetes were defined as fasting glucose $\geq 126$ or $100 \mathrm{mg} / \mathrm{dL}$ and/or $\mathrm{HbA1C}$ $\geq 6.5 \%$ or $5.7 \%$ (respectively) and/or use of diabetic medications.

\subsection{Nutritional and Lifestyle Variables Evaluation and Definitions}

The semi-quantitative FFQ, which was assembled by the Food and Nutrition Administration, Ministry of Health and tailored to the Israeli population, is composed of 117 food items with specified serving sizes. For each food item, participants indicated their average frequency of consumption over the past year. The nutrient components were obtained from the Israeli National Nutrient Database (BINAT), Ministry of Health. Vitamin intake was calculated as $\mathrm{mg} /$ day. Since subjects with high vitamin intake also consume more calories, we corrected vitamin consumption per $1000 \mathrm{Kcal}$. High intake of vitamins was defined as above the study upper tertile (corresponding to for vitamin $\mathrm{E} \geq 8.43,8.40$, $8.48 \mathrm{mg} / 1000 \mathrm{Kcal}$ for total population, women or men; for vitamin $C \geq 97.83,102.84,94.93 \mathrm{mg} / 1000 \mathrm{Kcal}$ for total population, women or men, respectively).

\subsection{Determination of Malondialdehyde Serum Levels}

Malondialdehyde was extracted from serum samples by treatment with 20 percent TCA at ration of 1:1. The serum samples were centrifuge at $8000 \mathrm{rpm}$ and filtered through a $0.2 \mu \mathrm{m}$ membrane. The supernatant was treated Thiobarbituric acid $(20 \mathrm{mM})$ and boiled in a water bath for $60 \mathrm{~min}$. A $10 \mu \mathrm{L}$ sample was injected into an high-performance liquid chromatography (HPLC) (Merck Hitachi) and separated with a C-18 phanomenex column, model RP-18, and detected with an HPLC fluorescence detector (Shimadzu, Japan) set at $532 \mathrm{~nm}$ excitation and $553 \mathrm{~nm}$ emission. The mobile phase consisted of a 35:65 (v/v) mixture of methanol and $0.05 \mathrm{M}$ potassium phosphate buffer, $\mathrm{pH} 7$, and the flow rate was $1 \mathrm{~mL} / \mathrm{min}$. MDA standard solutions were used to generate a standard curve. The nM levels of MDA found by us in the tested cohort are in agreement with serum MDA levels previously found in human after several hours of fasting [29]. High MDA levels were defined above the sample median corresponding to $12.87,12.10$, and 13.46 (nM) among the entire sample, men and women, respectively.

\subsection{Statistical Analysis}

Statistical analyses were performed using SPSS version 25 (IBM-SPSS Armonk, NY) software. Continuous variables are presented as means \pm SD. To test differences in continuous variables between two groups, the independent samples t-test was performed. Associations between nominal variables were performed with the Pearson Chi-Square test, and P for trend was calculated (Linear-by-Linear association of Chi-Square test) when needed. A multivariate logistic regression analysis was performed to test the adjusted association between MDA and NAFLD, NASH or fibrosis, or between vitamin E or $\mathrm{C}$ and MDA, adjusting for potential confounders (relevant variables which were different between the levels of serum MDA as depicted in Table 1). Odds ratio (OR) and $95 \%$ confidence interval (CI) are presented. $P$ value of $<0.05$ was considered statistically significant for all analyse. 


\section{Results}

3.1. Description of the Study Population and Comparison between Subjects with High (by Median) and Low $M D A$

Out of 970 subjects who participated in the study, 789 were eligible as previously described [30]. From those, 395 had available serum samples for the serum MDA measurements (one sample was excluded due to extreme result), 53\% were men, mean age was $59.15 \pm 6.45$ years and mean body mass index (BMI) was $28.35 \pm 5.51 \mathrm{Kg} / \mathrm{m}^{2}$. NAFLD was diagnosed by AUS in $37 \%(\mathrm{n}=146)$. Reliable FibroMax test was obtained from 379 subjects (15 had no serum sample). Presumed NASH was observed in $30.9 \%(n=117)$ and presumed significant fibrosis in $6.3 \%(n=24)$ (Figure 1).

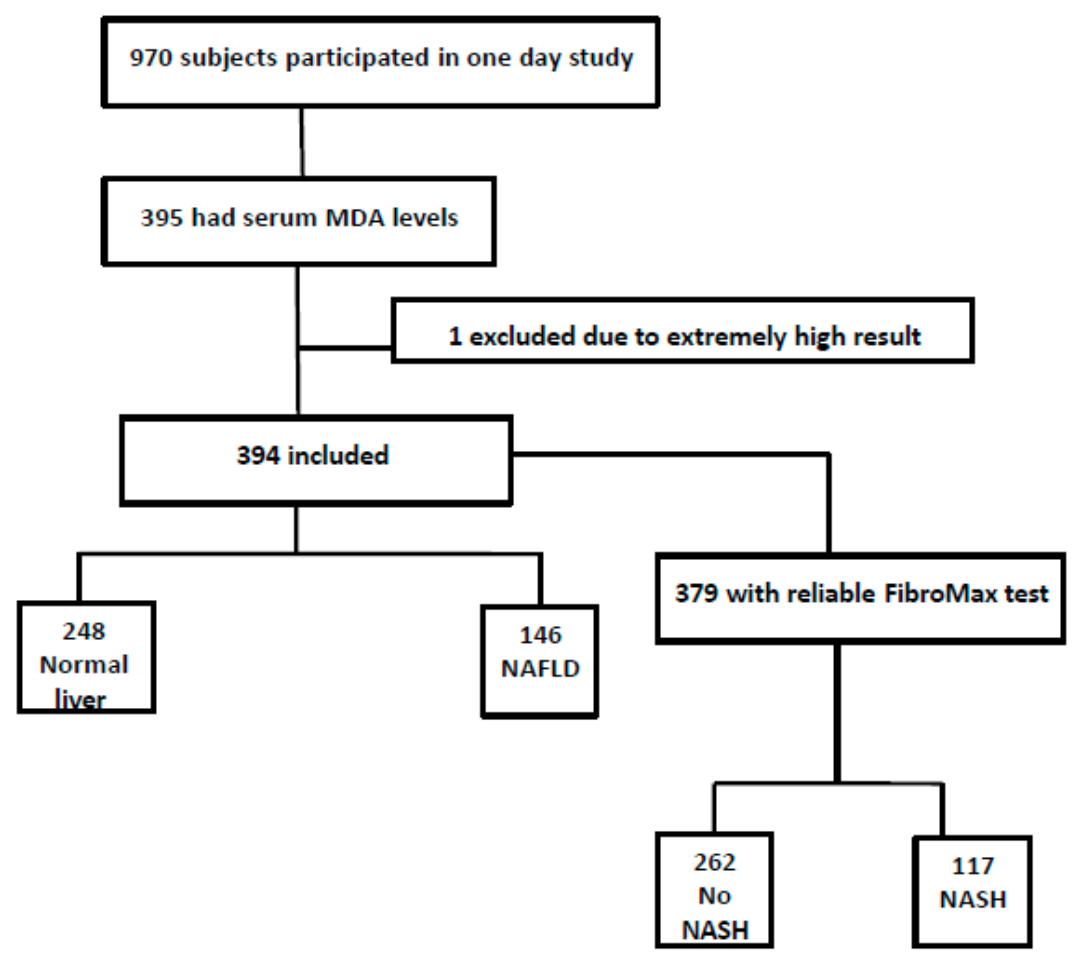

Figure 1. Flow chart of study population.

There was a significant difference of serum MDA levels between men and woman $(14.37 \pm 6.50 \mathrm{vs}$. $17.89 \pm 9.79 \mathrm{nM}, p<0.001$, respectively), and we stratified the results by gender to explore potential modifying effect of gender. Indeed, mean serum MDA levels [ \pm standard error (SE)] were higher among men with NAFLD vs. those without and among men with presumed NASH vs. those without, but no differences were noted among women (Figure A1).

Women with higher serum MDA levels had lower BMI and waist circumference. Men with higher serum MDA levels had higher levels of fasting glucose and $\mathrm{HbAI} 1 \mathrm{C}(\%)$, higher ALT levels and NASH-test score, consumed significantly more calories per day and saturated fatty acids (SFA) as percent of total calories. Both women and men with higher serum MDA levels had higher aspartate transaminase (AST) levels, consumed significantly less sugared beverages and vitamin E (per 1000 daily calories), but more cups of coffee (Table 1). The variables that differed between subjects with low and high MDA levels were considered as potential confounders in the multivariable analysis. 
Table 1. Comparison between subjects with high and low malondialdehyde (MDA) (by gender specific median, $\mathrm{nM})(\mathrm{Mean} \pm \mathrm{SD}$, unless otherwise stated).

\begin{tabular}{|c|c|c|c|c|c|c|}
\hline \multirow{2}{*}{$\begin{array}{c}\text { Variable } \\
\text { (Units, Normal Range) }\end{array}$} & \multicolumn{3}{|c|}{ Women } & \multicolumn{3}{|c|}{ Men } \\
\hline & $\begin{array}{c}\text { MDA }<13.46 \\
(n=92)\end{array}$ & $\begin{array}{c}\mathrm{MDA} \geq 13.46 \\
\quad(\mathrm{n}=93)\end{array}$ & $p$ Value & $\begin{array}{c}\text { MDA < 12.10 } \\
(n=104)\end{array}$ & $\begin{array}{c}\mathrm{MDA} \geq 12.10 \\
(\mathrm{n}=105)\end{array}$ & $p$ Value \\
\hline Age (years) & $58.50 \pm 6.92$ & $59.73 \pm 6.26$ & 0.206 & $59.06 \pm 6.59$ & $59.30 \pm 6.09$ & 0.787 \\
\hline $\mathrm{BMI}\left(\mathrm{Kg} / \mathrm{m}^{2}\right)$ & $28.76 \pm 6.20$ & $26.53 \pm 4.43$ & 0.006 & $29.45 \pm 6.19$ & $28.50 \pm 4.65$ & 0.214 \\
\hline Waist Circumference (cm) & $96.27 \pm 14.55$ & $92.07 \pm 11.95$ & 0.033 & $105.27 \pm 12.57$ & $103.42 \pm 13.50$ & 0.309 \\
\hline HOMA-IR (score) & $2.61 \pm 1.86$ & $2.49 \pm 2.10$ & 0.682 & $3.05 \pm 2.14$ & $3.04 \pm 1.89$ & 0.990 \\
\hline HbA1C (\%) & $5.82 \pm 0.50$ & $5.85 \pm 0.61$ & 0.671 & $5.77 \pm 0.56$ & $6.10 \pm 1.01$ & 0.004 \\
\hline Triglyceride (mg/dl) & $101.73 \pm 48.39$ & $107.44 \pm 53.15$ & 0.446 & $122.70 \pm 81.71$ & $116.04 \pm 76.63$ & 0.544 \\
\hline Total Cholesterol (mg/dl) & $186.13 \pm 33.18$ & $192.48 \pm 38.62$ & 0.232 & $167.73 \pm 30.66$ & $171.30 \pm 36.14$ & 0.443 \\
\hline ALT (U/L, 5-39) & $22.70 \pm 13.51$ & $24.38 \pm 10.08$ & 0.338 & $23.92 \pm 11.29$ & $27.54 \pm 11.65$ & 0.024 \\
\hline AST (U/L, 7-40) & $22.81 \pm 11.16$ & $26.19 \pm 10.30$ & 0.033 & $22.38 \pm 6.15$ & $25.10 \pm 7.00$ & 0.003 \\
\hline GGT (U/L, 6-28) & $29.85 \pm 37.65$ & $25.25 \pm 27.62$ & 0.345 & $27.91 \pm 18.18$ & $29.50 \pm 28.96$ & 0.637 \\
\hline NashTest (score) & $0.40 \pm 0.17$ & $0.45 \pm 0.15$ & 0.022 & $0.42 \pm 0.12$ & $0.48 \pm 0.13$ & 0.001 \\
\hline NASH (\%) & 28.10 & 31.50 & 0.623 & 23.20 & 40.20 & 0.010 \\
\hline FibroTest (score) & $0.16 \pm 0.12$ & $0.14 \pm 0.11$ & 0.291 & $0.25 \pm 0.16$ & $0.27 \pm 0.17$ & 0.405 \\
\hline Significant Fibrosis (\%) & 2.20 & 2.20 & 1.00 & 7.10 & 12.70 & 0.179 \\
\hline Uric Acid (mg/dl, 2.3-6) & $4.88 \pm 1.20$ & $4.87 \pm 1.23$ & 0.982 & $5.93 \pm 1.23$ & $6.07 \pm 1.19$ & 0.401 \\
\hline C-Reactive Protein $(\mathrm{mg} / \mathrm{L},<5)$ & $4.15 \pm 4.91$ & $3.99 \pm 5.43$ & 0.837 & $4.10 \pm 7.63$ & $3.71 \pm 6.02$ & 0.676 \\
\hline \multicolumn{7}{|c|}{ Nutritional and lifestyle habits } \\
\hline Energy (Kcal) & $2153.82 \pm 702.57$ & 1971. $84 \pm 644.25$ & 0.068 & $2253.95 \pm 740.16$ & 2031. $67 \pm 712.68$ & 0.028 \\
\hline Saturate Fatty Acid (\% of total Kcal/d) & $12.48 \pm 3.97$ & $12.34 \pm 4.68$ & 0.827 & $11.49 \pm 3.24$ & $12.54 \pm 3.93$ & 0.036 \\
\hline Cholesterol (mg/d) & $337.28 \pm 225.02$ & $290.57 \pm 131.96$ & 0.088 & $367.35 \pm 195.32$ & $364.40 \pm 239.01$ & 0.922 \\
\hline Fiber (gr/d) & $23.95 \pm 12.98$ & $23.17 \pm 10.86$ & 0.659 & $23.95 \pm 13.07$ & $21.60 \pm 12.45$ & 0.184 \\
\hline Red/Processed Meat (portions/d) & $0.40 \pm 0.66$ & $0.33 \pm 0.44$ & 0.428 & $0.90 \pm 1.13$ & $0.76 \pm 1.01$ & 0.340 \\
\hline
\end{tabular}


Table 1. Cont.

\begin{tabular}{|c|c|c|c|c|c|c|}
\hline \multirow{2}{*}{$\begin{array}{c}\text { Variable } \\
\text { (Units, Normal Range) }\end{array}$} & \multicolumn{3}{|c|}{ Women } & \multicolumn{3}{|c|}{ Men } \\
\hline & $\begin{array}{c}\text { MDA }<13.46 \\
(n=92)\end{array}$ & $\begin{array}{c}\text { MDA } \geq 13.46 \\
(n=93)\end{array}$ & $p$ Value & $\begin{array}{c}\text { MDA < 12.10 } \\
(\mathrm{n}=104)\end{array}$ & $\begin{array}{c}\text { MDA } \geq 12.10 \\
(n=105)\end{array}$ & $p$ Value \\
\hline Total Fish (portions/d) & $0.42 \pm 0.48$ & $0.55 \pm 0.68$ & 0.151 & $0.51 \pm 0.46$ & $0.58 \pm 0.54$ & 0.332 \\
\hline $\begin{array}{c}\text { Sugared Beverages } \\
\text { (cups/d) }\end{array}$ & $3.71 \pm 4.09$ & $2.11 \pm 3.61$ & 0.005 & $3.87 \pm 3.96$ & $2.02 \pm 3.31$ & $<0.001$ \\
\hline Coffee (cups/d) & $2.56 \pm 2.82$ & $3.49 \pm 3.46$ & 0.048 & $2.41 \pm 2.71$ & $3.48 \pm 3.47$ & 0.014 \\
\hline Alcohol (portions/d) & $0.73 \pm 1.79$ & $0.76 \pm 1.51$ & 0.902 & $2.55 \pm 3.63$ & $2.42 \pm 3.53$ & 0.785 \\
\hline Vitamin E (mg/ 1000 Kcal) & $9.65 \pm 6.77$ & $7.53 \pm 6.64$ & 0.033 & $9.28 \pm 6.67$ & $6.16 \pm 5.44$ & $<0.001$ \\
\hline Vitamin C (mg/ 1000 Kcal) & $89.41 \pm 58.54$ & $91.78 \pm 71.94$ & 0.806 & $92.20 \pm 61.17$ & $79.01 \pm 46.51$ & 0.081 \\
\hline Pack Years * & $11.23 \pm 18.66$ & $12.19 \pm 23.42$ & 0.758 & $19.86 \pm 25.24$ & $18.68 \pm 25.30$ & 0.735 \\
\hline Physical Activity (hours/week) & $1.60 \pm 2.66$ & $2.37 \pm 3.21$ & 0.076 & $1.90 \pm 3.52$ & $2.76 \pm 3.54$ & 0.079 \\
\hline
\end{tabular}

Malondialdehyde, MDA; body mass index, BMI; homeostatic model assessment for insulin resistance, HOMA-IR; Alanine aminotransferase, ALT; aspartate transaminase, AST; Gamma-glutamyl transferase, GGT. * Pack years were defined as cigarettes per day divided by 20 cigarettes per pack, multiplied by years of smoking. Never smokers were considered as zero. 
3.2. Dose-Response Association of MDA Levels and NAFLD among the Entire Study Sample and by Gender

In a univariate analysis, the prevalence of NAFLD was higher across increased levels of serum MDA in a dose-response manner (Figure 2(A-1)). In a multivariate analysis the odds for NAFLD were significantly higher with the rise of serum MDA levels in a dose-response manner, adjusting for age, gender, BMI and energy intake (Figure 2(B-1), model A), and with further adjustment for additional lifestyle habits (Figure 2(B-1), model B). Stratification of this analysis by gender, revealed a dose-response association among men, but not among women (Figure 2(B-3,B-2) respectively).

A-1

$$
\text { P for trend }=0.050
$$

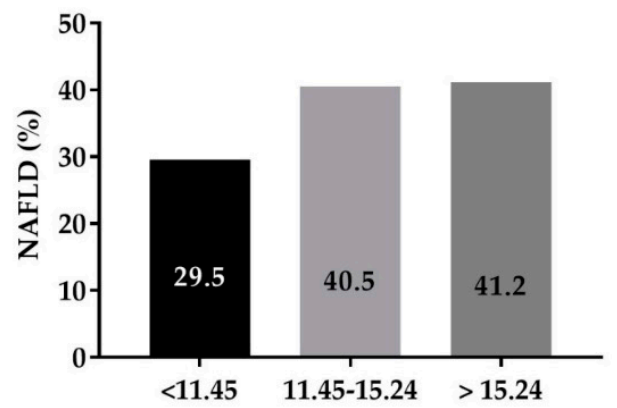

Serum MDA concentration (nM)

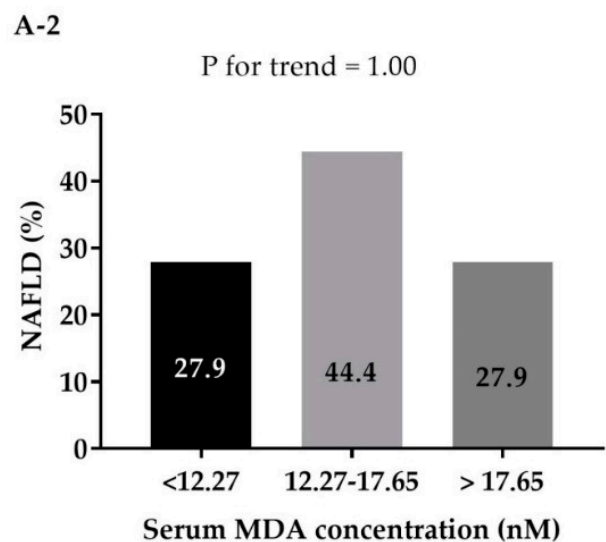

A-3

P for trend $=0.032$

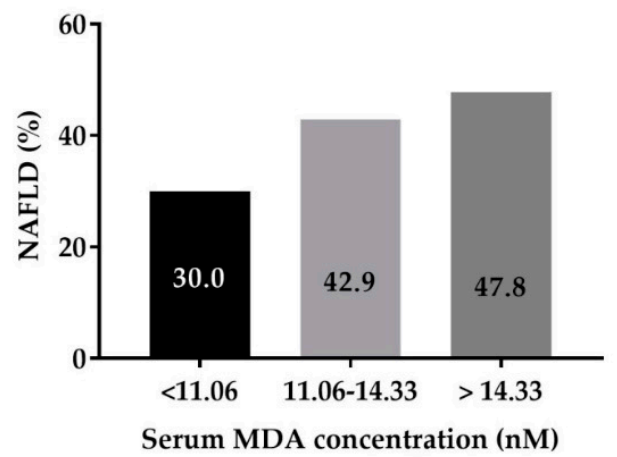

Figure 2. Cont. 

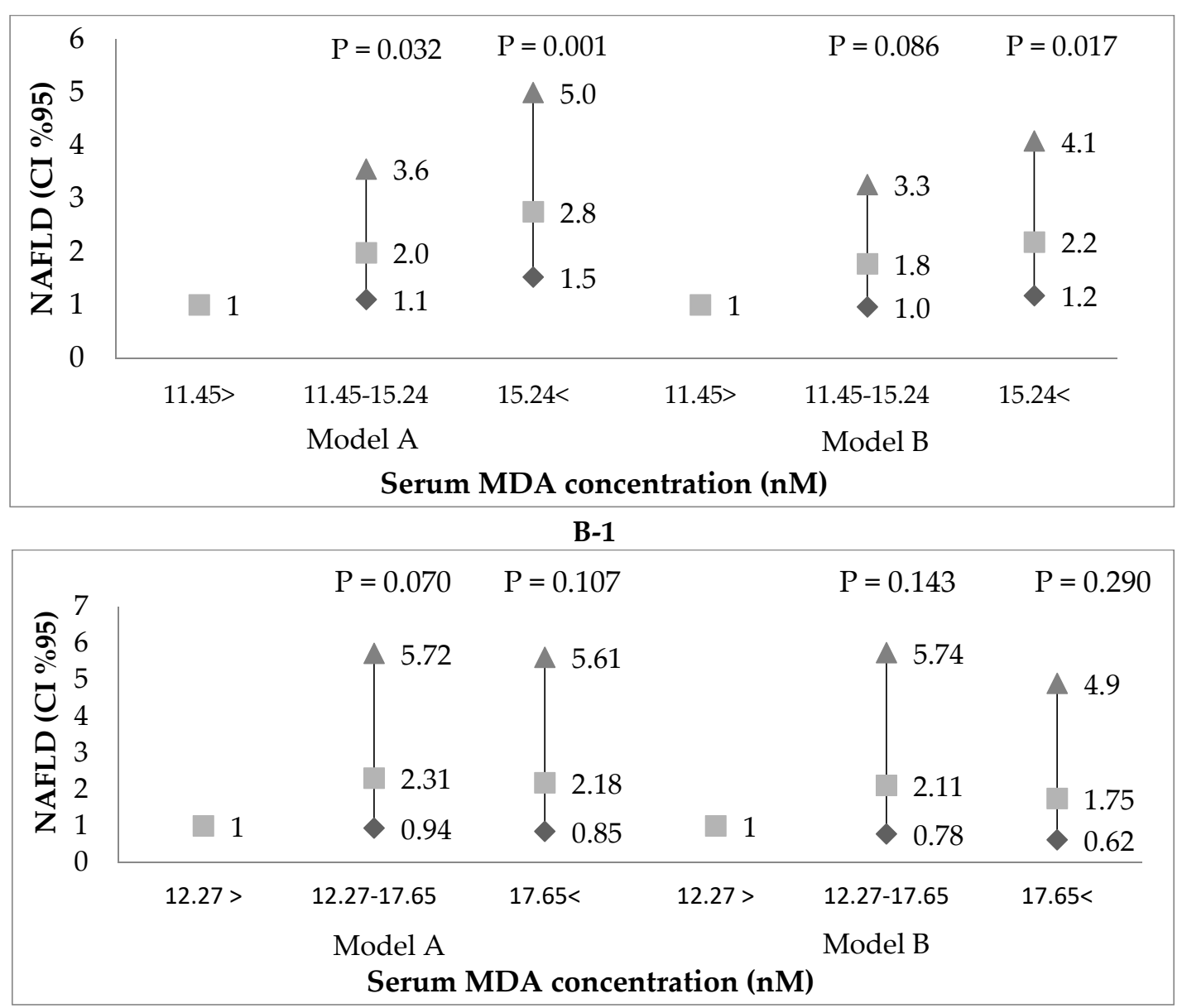

B-2

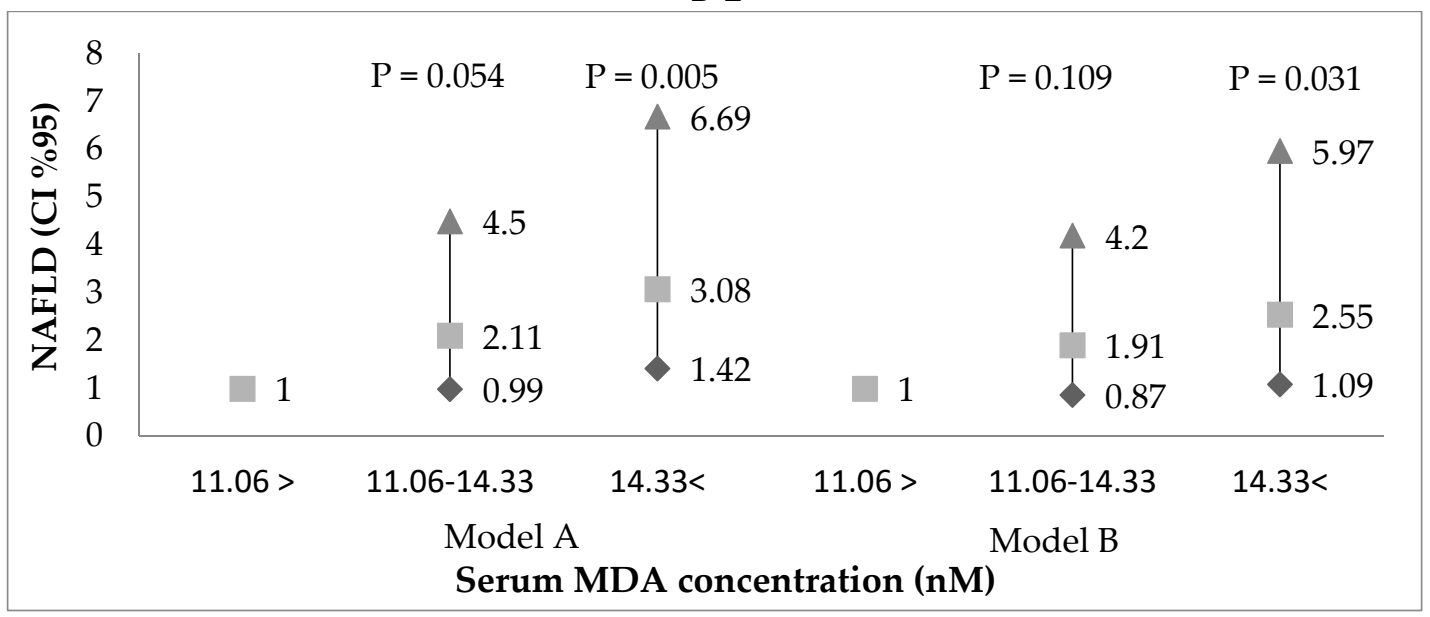

B-3

Figure 2. Univariate (A) and multivariate (B) dose response association between serum MDA concentration (nM) (tertiles, entire sample and gender specific) and NAFLD among the entire sample (A-1 and B-1), women (A-2 and B-2), and men (A-3 and B-3). In multivariate analysis Model ${ }^{\mathrm{A}}$ adjusted for: age (years), gender (in analysis of the entire sample), BMI $\left(\mathrm{Kg} / \mathrm{m}^{2}\right)$ and energy intake $(\mathrm{Kcal} / \mathrm{d}) . \mathrm{Model}^{\mathrm{B}}$ additionally adjusted for: pack years, physical activity (h/w) SFA (\% total Kcal) coffee (portions/d), total sugared beverages (portions/d) and A1C (\%). 
3.3. Multivariate Association of Serum MDA Levels and NAFLD and Presumed Related Liver Damage Stratified by Gender

In a multivariate analysis, adjusting for age (years), BMI $\left(\mathrm{Kg} / \mathrm{m}^{2}\right)$, energy (Kcal/day), gender, pack years, physical activity (h/w) SFA (\% total Kcal) coffee (portions/d), total sugared beverages (portions/d) and A1C (\%), the upper median of serum MDA levels was associated with NAFLD among the entire sample $(\mathrm{OR}=1.93,95 \% \mathrm{CI} 1.15-3.24, P=0.013)$. In addition, among men, the upper median of serum MDA was associated of higher odds for NAFLD and NASH and/or fibrosis (OR = 2.59, 95\% CI 1.33-5.07, $P=0.005 ; \mathrm{OR}=2.04,1.02-4.06, P=0.043$, respectively). There was no association between serum MDA and NAFLD or liver damage among women (Table 2).

Table 2. Multivariate association of serum MDA concentration (nM) and presumed related liver damage.

\begin{tabular}{|c|c|c|c|}
\hline & NAFLD & NASH & Fibrosis $\geq F 2$ or NASH \\
\hline & \multicolumn{3}{|c|}{ OR (95\% CI), P } \\
\hline All Samples (n Cases) ${ }^{a}$ & 146 & 117 & 121 \\
\hline \multicolumn{4}{|c|}{ Model A } \\
\hline$<12.87$ & 1 (ref) & 1 (ref) & 1 (ref) \\
\hline$\geq 12.87$ & $2.24(1.38-3.64), 0.001$ & $1.51(0.93-2.44), 0.094$ & $1.46(0.91-2.36) .0 .121$ \\
\hline \multicolumn{4}{|c|}{ Model B } \\
\hline$<12.87$ & 1 (ref) & 1 (ref) & 1 (ref) \\
\hline$\geq 12.87$ & $1.93(1.15-3.24), 0.013$ & 1.14 (0.69-1.90), 0.612 & $1.12(0.67-1.86), 0.666$ \\
\hline $\begin{array}{l}\text { Women } \\
\text { (n Cases) }\end{array}$ & 62 & 53 & 53 \\
\hline \multicolumn{4}{|c|}{ Model A } \\
\hline$<13.46$ & 1 (ref) & 1 (ref) & 1 (ref) \\
\hline$\geq 13.46$ & $1.69(0.79-3.63), 0.174$ & $1.10(0.53-2.31), 0.794$ & $\mathrm{~b}$ \\
\hline \multicolumn{4}{|c|}{ Model B } \\
\hline$<13.46$ & 1 (ref) & 1 (ref) & 1 (ref) \\
\hline$\geq 13.46$ & $1.37(0.60-3.14), 0.461$ & $0.84(0.37-1.87), 0.661$ & $\mathrm{~b}$ \\
\hline $\begin{array}{c}\text { Men } \\
\text { (n Cases) }\end{array}$ & 84 & 64 & 68 \\
\hline \multicolumn{4}{|c|}{ Model A } \\
\hline$<12.10$ & 1 (ref) & 1 (ref) & 1 (ref) \\
\hline$\geq 12.10$ & $2.87(1.53-5.37), 0.001$ & $2.20(1.16-4.21), 0.017$ & $2.22(1.17-4.21), 0.015$ \\
\hline \multicolumn{4}{|c|}{ Model B } \\
\hline$<12.10$ & 1 (ref) & 1 (ref) & 1 (ref) \\
\hline$\geq 12.10$ & 2.59 (1.33-5.07), 0.005 & $1.95(0.98-3.91), 0.059$ & $2.04(1.02-4.06), 0.043$ \\
\hline
\end{tabular}

\subsection{Multivariate Association of Vitamins E and C Intake and Serum MDA Levels Stratified by Gender}

In a multivariate analysis, adjusting for age, gender, BMI, pack years, physical activity, SFA, coffee, total sugared beverages and A1C, the upper tertile of vitamin E intake $(\mathrm{mg} / 1000 \mathrm{Kcal})$ was associated with lower odds of high serum MDA levels in the entire population and among women $(\mathrm{OR}=0.28$ $95 \%$ CI $0.13-0.62, P=0.002 ; \mathrm{OR}=0.27,0.08-0.92, P=0.036$, respectively). There was a similar tendency 
among men, but it did not reach statistical significance. No association was observed with vitamin $\mathrm{C}$ (Table 3).

Table 3. Multivariate association of vitamins $\mathrm{E}$ and $\mathrm{C}$ dietary intake and high MDA levels (above the sample median).

\begin{tabular}{|c|c|c|c|c|c|c|}
\hline \multirow[b]{2}{*}{ Variable } & \multicolumn{2}{|c|}{ All Sample ${ }^{a}$} & \multicolumn{2}{|c|}{ Women } & \multicolumn{2}{|c|}{ Men } \\
\hline & Value & $\begin{array}{c}\text { OR }(95 \% \text { CI }) \\
P\end{array}$ & Value & $\begin{array}{c}\text { OR }(95 \% \text { CI }) \\
P\end{array}$ & Value & $\begin{array}{c}\text { OR }(95 \% \mathrm{CI}) \\
\mathbf{P}\end{array}$ \\
\hline \multirow[b]{2}{*}{$\begin{array}{c}\text { Vitamin E (>upper tertile, } \\
\text { mg/1000 Kcal) }\end{array}$} & $<8.43$ & 1 (ref) & $<8.40$ & 1 (ref) & $<8.48$ & 1 (ref) \\
\hline & $\geq 8.43$ & $\begin{array}{c}0.28 \\
(0.13-0.62) \\
0.002\end{array}$ & $\geq 8.40$ & $\begin{array}{c}0.27 \\
(0.08-0.92) \\
0.036\end{array}$ & $\geq 8.48$ & $\begin{array}{c}0.37 \\
(0.13-1.08) \\
0.068\end{array}$ \\
\hline \multirow[b]{2}{*}{$\begin{array}{l}\text { Vitamin C (>upper tertile, } \\
\text { mg/1000 Kcal) intake }\end{array}$} & $<97.83$ & 1 (ref) & $<102.84$ & 1 (ref) & $<94.93$ & 1 (ref) \\
\hline & $\geq 97.83$ & $\begin{array}{c}1.12 \\
(0.63-1.97) \\
0.707\end{array}$ & $\geq 102.84$ & $\begin{array}{c}0.88 \\
(0.39-2.00) \\
0.766\end{array}$ & $\geq 94.93$ & $\begin{array}{c}1.03 \\
(0.47-2.24) \\
0.947\end{array}$ \\
\hline
\end{tabular}

Malondialdehyde, MDA. All models are adjusted for: age (years), BMI $\left(\mathrm{Kg} / \mathrm{m}^{2}\right)$, pack years, physical activity (h/w) SFA (\% total Kcal) coffee (portions/d), total sugared beverages (portions/d) and A1C (\%). ${ }^{a}$ additionaly adjusted for gender.

\section{Discussion}

Previously it was reported in small-scale studies that NASH patients are susceptible to increased levels of circulating lipid peroxidation products. Patients with NASH had higher levels of lipid peroxidation end-products with correlation to increase in cardiovascular risk [31]. Here we are demonstrating by evaluation of a large sample of people from a general population, that there is a strong independent association between NAFLD, presumed NASH and circulating levels of oxidized lipids. Interestingly, there was an interaction with gender, where the association was evident only in men. Our results also indicate strong inverse association of MDA levels and consumption of vitamin E, which may indicate lower antioxidant status.

There are only few epidemiological studies testing the independent association between serum MDA levels and NAFLD, none of them thoroughly adjusted for lifestyle risk factors or tested gender differences. In a study including 139 individuals with type-2 diabetes, MDA was an independent predictor of higher fatty liver index (FLI) as a marker for NAFLD [32]. Similarly, a study conducted on 300 patients with type-2 diabetes, MDA was elevated in AUS diagnosed NAFLD patients [33]. An association between MDA levels and disease severity has been demonstrated in small sample studies with liver biopsy. In a small study including 32 patients with biopsy-proven NAFLD, both serum MDA and tissue MDA were independently associated with increased homeostatic model assessment for insulin resistance (HOMA-IR), and increased MDA was a risk factor for NASH [34]. Similar findings were demonstrated in 67 patients with NAFLD or NASH, where serum MDA was significantly elevated in NAFLD and NASH groups compared to controls [35]. Considering the fact that NAFLD and NASH improve with weight reduction [36], another support for our findings is the reduction in MDA levels following lifestyle or bariatric interventions. Elevations in hepatic lipid peroxidation improve significantly with weight loss induced by bariatric surgery, as indicated by liver biopsies from 20 NAFLD patients [37]. Similarly, dietary intervention followed by weight reduction led to reduction in serum MDA levels [38]. Specifically, the Dietary Approaches to Stop Hypertension (DASH) diet, that is abundant with antioxidants, designed to be rich in fruits, vegetables, and whole grains, led to reduction in serum levels of inflammatory markers including MDA among patients with NAFLD [39].

In animal models, the severity of NASH was correlated to ferroptosis (death of cells by lipid peroxidation). Elevated arachidonic acid metabolism was reported to promote ferroptosis in methionine-choline deficient diet fed mouse livers, which was further demonstrated by lipid ROS accumulation, morphological change of mitochondria and increased cell death [40]. Age-related fibrosis 
in NASH patients was also connected to changes in redox cellular status. Fibrosis was demonstrated to be modulated by p52Shc/NOX2 that results in redox stress, and accelerated fibrosis in the aged due to increased production of hydrogen peroxides and superoxides that can promote lipid peroxidation as was demonstrated in old mice [41].

The reason why women are more protected against hepatic production of oxidized lipids could be related to the effect of estrogen. Indeed, direct evidence can be observed by treatment with 17beta-estradiol in aging male rats. Such treatment has a protective effect and prevented increase in lipid peroxidation, hepatic dysfunction and histological changes [42]. Another study demonstrated that ovariectomy in female rat can cause lipid peroxidation in liver tissues, while estradiol and progesterone supplementations to the ovariectomized rats protect against lipid peroxidation to a large extent [43].

In this study, we found an inverse association between dietary vitamin E intake and serum MDA levels among women, similar tendency was noted in men but it did not reach statistical significance. No similar association was noted with vitamin $C$. We have previously found in the same study population, that vitamin $\mathrm{E}$ and vitamin $\mathrm{C}$ intake were associated with lower odds of NAFLD and NASH [44]. These finding imply that the protective effect of vitamin E, as a fat-soluble antioxidant, may be mediated, at least partially, by reduction of MDA levels among women. Conversely, vitamin C, as a water soluble vitamin, may act through different mechanisms, but, of course, no causal inference can be determined in a cross-sectional study. Indeed, vitamin E consumption has been demonstrated among humans, to have a favorable effect in reduction of NASH, but not fibrosis $[45,46]$. However, while the recommended intake of vitamin E for adults is $15 \mathrm{mg} /$ day (or $22.4 \mathrm{IU} /$ day) [47], the supplements studies contained 400-800 IU. Since high dose vitamin E supplement raises some concerns regarding increased risk for mortality [48], hemorrhagic stroke [49] and prostate cancer [50], testing a potential protective effect of a lower dose provided by diet is appealing. Vitamin E is one of the most powerful chain-breaking antioxidants in the human body and has the ability to repress peroxidation and inhibit the expression of transforming growth factor-beta, which has been associated with hepatic fibrosis and hepatocyte apoptosis by activating hepatic stellate cells. By preventing the nuclear localization of NF- $\kappa \mathrm{B}$, decreasing COX-2 expression, and suppressing the expression of cytokines, vitamin E is able to dampen the inflammatory response in NAFLD [51]. In addition, immuno-histological evaluation demonstrated that vitamin E modulation decreases the Hedgehog response in the liver, which is elevated in chronic liver injury and promotes fibrosis and inflammation [52].

The best sources of vitamin E are nuts, seeds, plant oils, green leafy vegetables, and fortified cereals [47]. Therefore, it may be that higher vitamin E intake is an indicator for a better diet. To control for that, we adjusted the association for caloric intake as well as for major dietary components and other lifestyle behaviors as smoking and physical activity, and the association with MDA persisted. The fact that there was an association only with vitamin $E$ and not with vitamin $C$ intake, which is also a marker for a better nutrition in general, strengthen the assumption that vitamin $\mathrm{E}$ has a specific association with lower MDA levels.

The strengths of the study include its large sample size and meticulous assessment of dietary intake as well as other lifestyle parameters that could be controlled for. We were also able to reveal gender differences. However, this study has several limitations to consider. First, the cross-sectional design of the study does not allow causal inference. Second, dietary habits were self-reported and thus prone to a report bias. However, since the participants and the research team were both blinded to the AUS and FibroMax results, it is a non-differential repot bias and therefore may have only weakened the observed associations. Third, the diagnosis of NAFLD and presumed NASH or fibrosis were determined by AUS and FibroMax markers, respectively, and not by liver histology, which cannot be performed in a sample of apparently healthy volunteers. However, AUS it is the most accepted and common screening method for NAFLD in a general population. The FibroTest validity has been demonstrated in several studies and biomarkers of fibrosis are considered as reasonably acceptable non-invasive procedures, but as for the reference NashTest, although validated, non-invasive tests are still considered to be insufficient for the diagnosis of NASH. 


\section{Conclusions}

Serum MDA is strongly associated with NAFLD and markers of NASH or fibrosis among men. Dietary vitamin E intake seems to be protective from elevated MDA levels among women, suggesting a pathway for its protective role in NAFLD and mainly NASH. Prospective studies are needed to confirm these findings.

Author Contributions: S.Z.-S. conceived and designed the study, conducted on data collection and analysis and Wrote the manuscript, D.I.-W. did the date collection, data analysis and wrote the manuscript, N.F.-I. designed the study and did the date collection, M.H. did the MDA tests, M.W. did the ultrasound examinations, O.S. supervised on the study design and data collection, R.K. conceived and designed the study, conducted on data collection, O.T. conceived the study, led the MDA tests and wrote the manuscript. All authors have read and agreed to the published version of the manuscript.

Funding: Research Grants and Fellowships Fund on Food and Nutrition and their Implications on Public Health, The Israeli Ministry of Health.

Conflicts of Interest: The authors declare no conflict of interest.

\section{Appendix A}

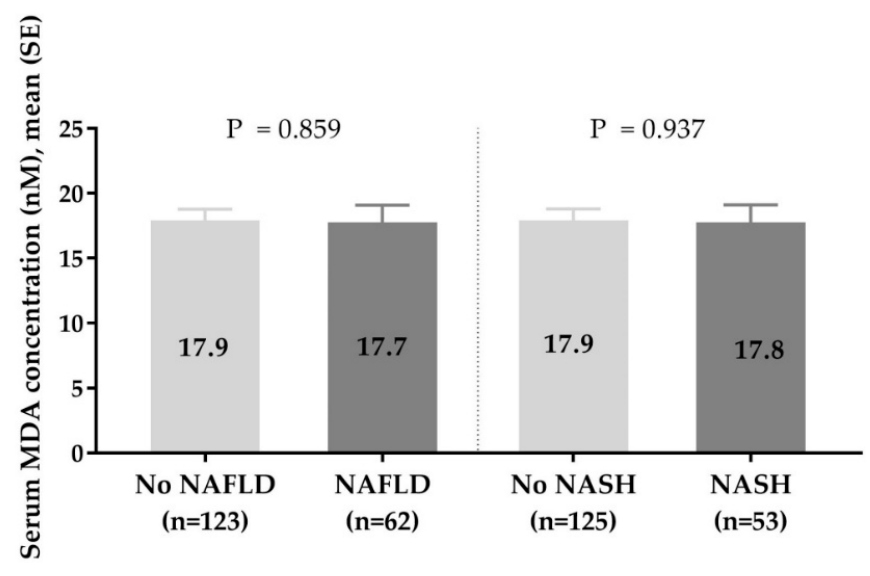

Women

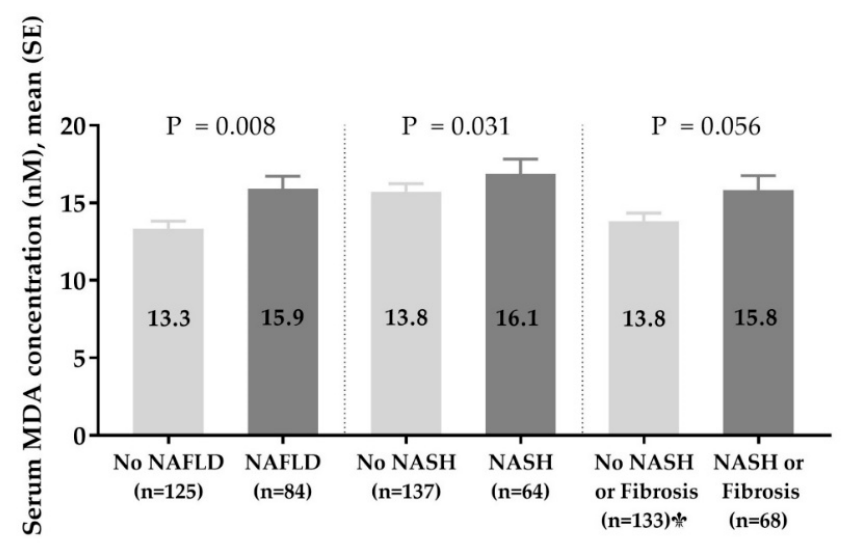

Men

Figure A1. Mean serum MDA levels [ \pm standard error (SE)] across non-alcoholic fatty liver disease (NAFLD) and steatohepatitis (NASH) diagnosis, stratified by gender. (Malondialdehyde, MDA Note: Among women, there were no cases of significant fibrosis that were without NASH, thus no results are presented in this category.) 


\section{References}

1. Younossi, Z.M. Non-alcoholic fatty liver disease-A global public health perspective. J. Hepatol. 2019, 70, 531-544. [CrossRef] [PubMed]

2. Bellentani, S.; Tiribelli, C. Is it time to change NAFLD and NASH nomenclature? Lancet Gastroenterol. Hepatol. 2017, 2, 547-548. [CrossRef]

3. Wong, R.J.; Aguilar, M.; Cheung, R.; Perumpail, R.B.; Harrison, S.A.; Younossi, Z.M.; Ahmed, A. Nonalcoholic steatohepatitis is the second leading etiology of liver disease among adults awaiting liver transplantation in the United States. Gastroenterology 2015, 148, 547-555. [CrossRef]

4. Bellanti, F.; Villani, R.; Facciorusso, A.; Vendemiale, G.; Serviddio, G. Lipid oxidation products in the pathogenesis of non-alcoholic steatohepatitis. Free Radic. Biol. Med. 2017, 111, 173-185. [CrossRef]

5. Hardwick, R.N.; Fisher, C.D.; Canet, M.J.; Lake, A.D.; Cherrington, N.J. Diversity in antioxidant response enzymes in progressive stages of human nonalcoholic fatty liver disease. Drug Metab. Dispos. 2010, 38, 2293-2301. [CrossRef]

6. Mansouri, A.; Gattolliat, C.H.; Asselah, T. Mitochondrial Dysfunction and Signaling in Chronic Liver Diseases. Gastroenterology 2018, 155, 629-647. [CrossRef] [PubMed]

7. Ucar, F.; Sezer, S.; Erdogan, S.; Akyol, S.; Armutcu, F.; Akyol, O. The relationship between oxidative stress and nonalcoholic fatty liver disease: Its effects on the development of nonalcoholic steatohepatitis. Redox Rep. 2013, 18, 127-133. [CrossRef]

8. Hadizadeh, F.; Faghihimani, E.; Adibi, P. Nonalcoholic fatty liver disease: Diagnostic biomarkers. World J. Gastrointest. Pathophysiol. 2017, 8, 11. [CrossRef] [PubMed]

9. Yesilova, Z.; Yaman, H.; Oktenli, C.; Ozcan, A.; Uygun, A.; Cakir, E.; Sanisoglu, S.Y.; Erdil, A.; Ates, Y.; Aslan, M.; et al. Systemic markers of lipid peroxidation and antioxidants in patients with nonalcoholic Fatty liver disease. Am. J. Gastroenterol. 2005, 100, 850-855. [CrossRef]

10. Varma, M.; Makwane, H.; Kare, P.; Jha, R.; Parmar, A. Study of serum ferritin, serum uric acid and plasma malondialdehyde (MDA) levels in non-alcoholic fatty liver disease. Int. J. Biomed. Adv. Res. 2016, 7, 169. [CrossRef]

11. Albano, E.; Mottaran, E.; Vidali, M.; Reale, E.; Saksena, S.; Occhino, G.; Burt, A.; Day, C. Immune response towards lipid peroxidation products as a predictor of progression of non-alcoholic fatty liver disease to advanced fibrosis. Gut 2005, 54, 987-993. [CrossRef]

12. Kumar, A.; Sharma, A.; Duseja, A.; Das, A.; Dhiman, R.K.; Chawla, Y.K.; Kohli, K.K.; Bhansali, A. Patients with nonalcoholic fatty liver disease (NAFLD) have higher oxidative stress in comparison to chronic viral hepatitis. J. Clin. Exp. Hepatol. 2013, 3, 12-18. [CrossRef]

13. Gee, P.T. Unleashing the untold and misunderstood observations on vitamin E. Genes Nutr. 2011, 6, 5-16. [CrossRef] [PubMed]

14. El Hadi, H.; Vettor, R.; Rossato, M. Vitamin E as a Treatment for Nonalcoholic Fatty Liver Disease: Reality or Myth? Antioxidants 2018, 7, 12. [CrossRef]

15. Chen, G.; Ni, Y.; Nagata, N.; Xu, L.; Ota, T. Micronutrient Antioxidants and Nonalcoholic Fatty Liver Disease. Int. J. Mol. Sci. 2016, 17, 1379. [CrossRef]

16. Phung, N.; Pera, N.; Farrell, G.; Leclercq, I.; Hou, J.Y.; George, J. Pro-oxidant-mediated hepatic fibrosis and effects of antioxidant intervention in murine dietary steatohepatitis. Int. J. Mol. Med. 2009, 24, 171-180.

17. Nan, Y.M.; Wu, W.J.; Fu, N.; Liang, B.L.; Wang, R.Q.; Li, L.X.; Zhao, S.X.; Zhao, J.M.; Yu, J. Antioxidants vitamin $\mathrm{E}$ and 1-aminobenzotriazole prevent experimental non-alcoholic steatohepatitis in mice. Scand. J. Gastroenterol. 2009, 44, 1121-1131. [CrossRef]

18. Wei, J.; Lei, G.H.; Fu, L.; Zeng, C.; Yang, T.; Peng, S.F. Association between Dietary Vitamin C Intake and Non-Alcoholic Fatty Liver Disease: A Cross-Sectional Study among Middle-Aged and Older Adults. PLoS ONE 2016, 11, e0147985. [CrossRef]

19. Han, J.M.; Jo, A.N.; Lee, S.M.; Bae, H.S.; Jun, D.W.; Cho, Y.K.; Suk, K.T.; Yoon, J.H.; Ahn, S.B.; Cho, Y.J.; et al. Associations between intakes of individual nutrients or whole food groups and non-alcoholic fatty liver disease among Korean adults. J. Gastroenterol. Hepatol. 2014, 29, 1265-1272. [CrossRef]

20. Da Silva, H.E.; Arendt, B.M.; Noureldin, S.A.; Therapondos, G.; Guindi, M.; Allard, J.P. A cross-sectional study assessing dietary intake and physical activity in Canadian patients with nonalcoholic fatty liver disease vs healthy controls. J. Acad. Nutr. Diet. 2014, 114, 1181-1194. [CrossRef] 
21. Chan, R.; Wong, V.W.; Chu, W.C.; Wong, G.L.; Li, L.S.; Leung, J.; Chim, A.M.; Yeung, D.K.; Sea, M.M.; Woo, J.; et al. Diet-Quality Scores and Prevalence of Nonalcoholic Fatty Liver Disease: A Population Study Using Proton-Magnetic Resonance Spectroscopy. PLoS ONE 2015, 10, e0139310. [CrossRef] [PubMed]

22. Wilett, W. Nutritional Epidemiology; Oxford University Press: New York, NY, USA, 1998.

23. Keinan-Boker, L.; Noyman, N.; Chinich, A.; Green, M.S.; Nitzan-Kaluski, D. Overweight and obesity prevalence in Israel: Findings of the first national health and nutrition survey (MABAT). Isr. Med. Assoc. J.: IMAJ 2005, 7, 219-223. [PubMed]

24. Gore, R. Diffuse liver disease. In Textbook of Gastrointestinal Radiology; Gore, R.M., Levin, M.S., Laufer, I., Eds.; Saunders: Philadelphia, PA, USA, 1994; pp. 1968-2017.

25. Zelber-Sagi, S.; Nitzan-Kaluski, D.; Goldsmith, R.; Webb, M.; Blendis, L.; Halpern, Z.; Oren, R. Long term nutritional intake and the risk for non-alcoholic fatty liver disease (NAFLD): A population based study. J. Hepatol. 2007, 47, 711-717. [CrossRef]

26. Munteanu, M.; Tiniakos, D.; Anstee, Q.; Charlotte, F.; Marchesini, G.; Bugianesi, E.; Trauner, M.; Romero Gomez, M.; Oliveira, C.; Day, C.; et al. Diagnostic performance of FibroTest, SteatoTest and ActiTest in patients with NAFLD using the SAF score as histological reference. Aliment. Pharmacol. Ther. 2016, 44, 877-889. [CrossRef] [PubMed]

27. Poynard, T.; Munteanu, M.; Charlotte, F.; Perazzo, H.; Ngo, Y.; Deckmyn, O.; Pais, R.; Merrouche, W.; de Ledinghen, V.; Mathurin, P.; et al. Diagnostic performance of a new noninvasive test for nonalcoholic steatohepatitis using a simplified histological reference. Eur. J. Gastroenterol. Hepatol. 2018, 30, 569-577. [CrossRef]

28. Poynard, T.; Munteanu, M.; Deckmyn, O.; Ngo, Y.; Drane, F.; Messous, D.; Castille, J.M.; Housset, C.; Ratziu, V.; Imbert-Bismut, F. Applicability and precautions of use of liver injury biomarker FibroTest. A reappraisal at 7 years of age. BMC Gastroenterol. 2011, 11, 39. [CrossRef] [PubMed]

29. Gorelik, S.; Ligumsky, M.; Kohen, R.; Kanner, J. A novel function of red wine polyphenols in humans: Prevention of absorption of cytotoxic lipid peroxidation products. FASEB J. 2008, 22, 41-46. [CrossRef] [PubMed]

30. Zelber-Sagi, S.; Ivancovsky-Wajcman, D.; Fliss Isakov, N.; Webb, M.; Orenstein, D.; Shibolet, O.; Kariv, R. High red and processed meat consumption is associated with non-alcoholic fatty liver disease and insulin resistance. J. Hepatol. 2018, 68, 1239-1246. [CrossRef]

31. Chalasani, N.; Deeg, M.A.; Crabb, D.W. Systemic Levels of Lipid Peroxidation and Its Metabolic and Dietary Correlates in Patients with Nonalcoholic Steatohepatitis; LWW: Philadelphia, PA, USA, 2004.

32. Klisic, A.; Isakovic, A.; Kocic, G.; Kavaric, N.; Jovanovic, M.; Zvrko, E.; Skerovic, V.; Ninic, A. Relationship between Oxidative Stress, Inflammation and Dyslipidemia with Fatty Liver Index in Patients with Type 2 Diabetes Mellitus. Exp. Clin. Endocrinol. Diabetes 2018, 126, 371-378. [CrossRef]

33. Vanjiappan, S.; Hamide, A.; Ananthakrishnan, R.; Periyasamy, S.G.; Mehalingam, V. Nonalcoholic fatty liver disease in patients with type 2 diabetes mellitus and its association with cardiovascular disease. Diabetes Metab. Syndr. 2018, 12, 479-482. [CrossRef]

34. Koroglu, E.; Canbakan, B.; Atay, K.; Hatemi, I.; Tuncer, M.; Dobrucali, A.; Sonsuz, A.; Gultepe, I.; Senturk, H. Role of oxidative stress and insulin resistance in disease severity of non-alcoholic fatty liver disease. Turk. J. Gastroenterol. 2016, 27, 361-366. [CrossRef] [PubMed]

35. Swiderska, M.; Maciejczyk, M.; Zalewska, A.; Pogorzelska, J.; Flisiak, R.; Chabowski, A. Oxidative stress biomarkers in the serum and plasma of patients with non-alcoholic fatty liver disease (NAFLD). Can plasma AGE be a marker of NAFLD? Oxidative stress biomarkers in NAFLD patients. Free Radic. Res. 2019, 53, 841-850. [CrossRef] [PubMed]

36. Romero-Gomez, M.; Zelber-Sagi, S.; Trenell, M. Treatment of NAFLD with diet, physical activity and exercise. J. Hepatol. 2017, 67, 829-846. [CrossRef] [PubMed]

37. Bell, L.N.; Temm, C.J.; Saxena, R.; Vuppalanchi, R.; Schauer, P.; Rabinovitz, M.; Krasinskas, A.; Chalasani, N.; Mattar, S.G. Bariatric surgery-induced weight loss reduces hepatic lipid peroxidation levels and affects hepatic cytochrome P-450 protein content. Ann. Surg. 2010, 251, 1041-1048. [CrossRef] [PubMed]

38. Kani, A.H.; Alavian, S.M.; Esmaillzadeh, A.; Adibi, P.; Azadbakht, L. Effects of a novel therapeutic diet on liver enzymes and coagulating factors in patients with non-alcoholic fatty liver disease: A parallel randomized trial. Nutrition 2014, 30, 814-821. [CrossRef] [PubMed] 
39. Razavi Zade, M.; Telkabadi, M.H.; Bahmani, F.; Salehi, B.; Farshbaf, S.; Asemi, Z. The effects of DASH diet on weight loss and metabolic status in adults with non-alcoholic fatty liver disease: A randomized clinical trial. Liver Int. 2016, 36, 563-571. [CrossRef]

40. Li, X.; Wang, T.X.; Huang, X.; Li, Y.; Sun, T.; Zang, S.; Guan, K.L.; Xiong, Y.; Liu, J.; Yuan, H.X. Targeting ferroptosis alleviates methionine-choline deficient (MCD)-diet induced NASH by suppressing liver lipotoxicity. Liver Int. 2020. [CrossRef]

41. Jiang, J.X.; Fish, S.R.; Tomilov, A.; Li, Y.; Fan, W.; Dehnad, A.; Gae, D.; Das, S.; Mozes, G.; Charville, G.W.; et al. Non-phagocytic Activation of NOX2 is Implicated in Progressive Non-alcoholic Steatohepatitis During Aging. Hepatology 2020. [CrossRef]

42. Mladenović, J.; Ognjanović, B.; Đorđević, N.; Matić, M.; Knežević, V.; Štajn, A.; Saičić, Z. Protective effects of oestradiol against cadmium-induced changes in blood parameters and oxidative damage in rats. Arch. Ind. Hyg. Toxic. 2014, 65, 37-46. [CrossRef] [PubMed]

43. Oztekin, E.; Tiftik, A.M.; Baltaci, A.K.; Mogulkoc, R. Lipid peroxidation in liver tissue of ovariectomized and pinealectomized rats: Effect of estradiol and progesterone supplementation. Cell Biochem. Funct. 2007, 25, 401-405. [CrossRef]

44. Ivancovsky-Wajcman, D.; Fliss-Isakov, N.; Salomone, F.; Webb, M.; Shibolet, O.; Kariv, R.; Zelber-Sagi, S. Dietary vitamin $\mathrm{E}$ and $\mathrm{C}$ intake is inversely associated with the severity of nonalcoholic fatty liver disease. Dig. Liver Dis. 2019, 51, 1698-1705. [CrossRef] [PubMed]

45. Sanyal, A.J.; Chalasani, N.; Kowdley, K.V.; McCullough, A.; Diehl, A.M.; Bass, N.M.; Neuschwander-Tetri, B.A.; Lavine, J.E.; Tonascia, J.; Unalp, A.; et al. Pioglitazone, vitamin E, or placebo for nonalcoholic steatohepatitis. N. Engl. J. Med. 2010, 362, 1675-1685. [CrossRef] [PubMed]

46. Lavine, J.E.; Schwimmer, J.B.; Van Natta, M.L.; Molleston, J.P.; Murray, K.F.; Rosenthal, P.; Abrams, S.H.; Scheimann, A.O.; Sanyal, A.J.; Chalasani, N.; et al. Effect of vitamin E or metformin for treatment of nonalcoholic fatty liver disease in children and adolescents: The TONIC randomized controlled trial. JAMA 2011, 305, 1659-1668. [CrossRef]

47. National Academy of Sciences. Dietary Reference Intakes (DRIs): Recommended Dietary Allowances and Adequate Intakes, Vitamins. 2011. Available online: www.ncbi.nlm.nih.gov/books/NBK56068/table/ summarytables.t2/?report=objectonly (accessed on 1 January 2020).

48. Miller, E.R., 3rd; Pastor-Barriuso, R.; Dalal, D.; Riemersma, R.A.; Appel, L.J.; Guallar, E. Meta-analysis: High-dosage vitamin E supplementation may increase all-cause mortality. Ann. Intern. Med. 2005, 142, 37-46. [CrossRef] [PubMed]

49. Schurks, M.; Glynn, R.J.; Rist, P.M.; Tzourio, C.; Kurth, T. Effects of vitamin E on stroke subtypes: Meta-analysis of randomised controlled trials. BMJ 2010, 341, c5702. [CrossRef]

50. Klein, E.A.; Thompson, I.M., Jr.; Tangen, C.M.; Crowley, J.J.; Lucia, M.S.; Goodman, P.J.; Minasian, L.M.; Ford, L.G.; Parnes, H.L.; Gaziano, J.M.; et al. Vitamin E and the risk of prostate cancer: The Selenium and Vitamin E Cancer Prevention Trial (SELECT). JAMA 2011, 306, 1549-1556. [CrossRef] [PubMed]

51. Perumpail, B.J.; Li, A.A.; John, N.; Sallam, S.; Shah, N.D.; Kwong, W.; Cholankeril, G.; Kim, D.; Ahmed, A. The Role of Vitamin E in the Treatment of NAFLD. Diseases 2018, 6, 86. [CrossRef]

52. Verdelho Machado, M.; Diehl, A.M. Role of Hedgehog Signaling Pathway in NASH. Int. J. Mol. Sci. 2016, 17, 857. [CrossRef]

(C) 2020 by the authors. Licensee MDPI, Basel, Switzerland. This article is an open access article distributed under the terms and conditions of the Creative Commons Attribution (CC BY) license (http://creativecommons.org/licenses/by/4.0/). 